\title{
Additive biomass equations for pine species of forest plantations of Durango, Mexico
}

\author{
José de Jesús Návar Cháidez ${ }^{1}$ \\ Nicolás González Barrientos ${ }^{2}$ \\ José de Jesús Graciano Luna ${ }^{3}$ \\ Virginia Dale ${ }^{4}$ \\ Bernard Parresol ${ }^{5}$
}

\begin{abstract}
Statistical analysis between three weighted additive biomass equations are presented for planted pine species typical of the coniferous forests of the Western Sierra Madre mountain range of Durango, Mexico. Statistical and graphical analyses were used to select the best single and multiple individual biomass component equation. Linear equations better fitted the biomass components. Therefore, three linear additive procedures were tested: (i) the conventional, (ii) a harmonization, and (iii) the seemingly-unrelated regression in two types of equations of component biomass estimation using both simple regression and multiple regression techniques. These tests were performed at two scales: (a) each of three pine species and (b) all three species. For both the simple linear and best multiple regression equation, the seemingly-unrelated equations provided more precise biomass component estimates, with tendencies consistent with the conventional non-additive non-linear regression procedures, and provided average biomass component estimates when equations were applied to a data set of 23 sample quadrants.
\end{abstract}

KEY WORDS:

Biomass additivity, P. cooperi, P. durangensis, P. engelmannii, seemingly unrelated regression.

\section{RESUMEN}

Se presentan análisis estadísticos entre tres ecuaciones aditivas ponderadas para el cálculo de la biomasa en plantaciones de especies de pino típicas de los bosques de coníferas de la Sierra Madre Occidental en el Estado de Durango, México. Se usaron análisis estadísticos y gráficos para seleccionar las mejores ecuaciones para los componentes de la biomasa, de manera individual o múltiple. Por lo tanto, se ensayaron tres procedimientos aditivos lineales: (i) el convencional, (ii) una armonización, y (iii) la regresión generalizada no relacionada en dos tipos de ecuaciones para estimación de los componentes de la biomasa utilizando técnicas tanto de regresión simple lineal como múltiple. Estas pruebas se llevaron a cabo en dos escalas: (a) cada una de las tres especies de pino y (b) las tres especies en conjunto. Tanto para las ecuaciones de regresión lineal simple como para las de regresión múltiple, las ecuaciones generalizadas no relacionadas dieron estimaciones más precisas de los componentes de la biomasa, con tendencias consistentes con los procedimientos convencionales no aditivos de regresión múltiple no lineal y arrojaron estimaciones promedio de los componentes de la biomasa cuando las ecuaciones se aplicaron a un conjunto de datos de una muestra de 23 cuadrantes.

PALABRAS CLAVE:

Aditividad de la biomasa, $P$. cooperi, $P$. durangensis, $P$. engelmannii, regresión generalizada no relacionada. 


\section{INTRODUCTION}

Estimating the environmental services provided by carbon sequestration requires the use of biomass estimates (Houghton, 1991; Brown, 1997). Several models estimate biomass or biomass-related parameters to assess the fate of $\mathrm{CO}_{2}$ in the biosphere (Mohren and Goldewijk, 1990). Given this importance, biomass equations have been compiled or developed for tropical, temperate, boreal, and semi-arid, sub-tropical trees (Schroeder et al., 1997; Ter-Mikaelian and Korzukhin, 1997; Návar et al., 2002).

A variety of regression models have been used for estimating total tree biomass or tree biomass components (Clutter et al., 1983), and they fall into three main forms: linear additive, nonlinear additive, and nonlinear multiplicative error (Parresol, 1999). A desirable feature of tree component regression equations is that the sum of predictions for the components equals the prediction for the total tree (Cunia and Briggs, 1984, 1985; Parresol, 1999). Procedures for forcing additivity have been proposed. Total biomass is estimated by (1) using the same independent variables for estimating each component, (2) adding the most appropriate regression functions of each biomass component, and (3) forcing the regression coefficients to estimate total biomass (Cunia and Briggs, 1985; Parresol, 1999). These procedures have been applied widely for temperate trees (Cunia and Briggs, 1985; Parresol, 1999) and semi-arid, subtropical trees (Návar et al., 2002). However, biomass component equations for young pine plantations that meet the additive requirements are rare in the scientific literature, when currently there is a wide range of forest plantations scattered over the Western Sierra Madre of Mexico. For the period between 1993 and 1998 approximately 5000 hectares were annually planted only in the State of
Durango. Regardless of their importance, no attempts have been made to quantify the environmental services provided by these forest plantations. The projection of carbon stocks in the early stages of forest plantations requires established additive biomass equations.

\section{OBJECTIVES}

The aim of this study was (1) to select the best single and multiple regression equation to estimate biomass components, (2) to fit three biomass additivity procedures in two different forms, (2) to compare efficiency in biomass estimates between two scales, and (3) to contrast biomass estimates among additive procedures in 23 planted forest stands of Durango, Mexico.

\section{MATERIALS AND METHODS}

This research was conducted in forests managed by the Unidad de Conservacion y Desarrollo Forestal No 6 of the Western Sierra Madre mountain range of Durango, Mexico. Forest plantations of several community-based land ownership, ejidos, including La Campana, San Pablo, La Ciudad, Los Bancos, La Victoria, located in the municipality of Pueblo Nuevo, Durango, were sampled. The ejidos are within the coordinates $105^{\circ} 36^{\prime} 19^{\prime \prime} \mathrm{W}$ and 10551'48' $\mathrm{W}$ and $24^{\circ} 19^{\prime} 05^{\prime \prime} \mathrm{N}$ and 24웅' $16^{\prime \prime} \mathrm{N}$ and lie between 2000 meters and 2900 meters above sea level (masl). The area is characterized by a cold-temperate climate with average annual long-term precipitation and temperature of $900 \mathrm{~mm}$ and 15 ${ }^{\circ} \mathrm{C}$, respectively. Plant cover is dominated by native, uneven aged, mixed coniferous forests. Pines and oaks are the most abundant genera in the western Sierra Madre mountain range. 
Methodology. Biomass components of 56 trees of $P$. durangensis (25), $P$. cooperii (19), and $P$. engelmannii (12) were measured. In each of 23 forest plantations, at least two trees were selected from each forest stand for biomass measurements. Trees were felled and separated into biomass components leaf, branch and stem. Biomass components were weighed fresh, and samples of $15 \%$ of each component were collected for ovendry analysis. All trees of each of the twenty-three forest plantations were measured in basal diameter (D), top height $(\mathrm{H})$, and canopy cover $(\mathrm{CT})$ (Table 1 ) in quadrants of $20 \mathrm{~m} \times 30 \mathrm{~m}$.

Additive biomass equations. Three procedures were used to develop the additive biomass component equations: (i) the conventional procedure (CON), (ii) a harmonization procedure (HAR), and (iii) seemingly-unrelated regression (SUR). Clutter et al. (1983) discuss a wide range of multiple equations that use top height, basal diameter, and interactions of these variables. These equations are classified as best regression models and they fall into the category of procedure $\mathrm{i}$. Cunia and Briggs (1985) defined harmonization, which falls within additive proce- dure ii. It causes the equations of individual biomass components to behave harmoniously and never exceeding biomass estimates of the upper compartment (i.e., bark would never exceed total stem biomass estimates). Procedure iii is an extension of procedures $\mathrm{CON}$ and HAR. Cunia and Briggs $(1984 ; 1985)$ and Parresol (1999) reported examples of SUR applied to additive best regression equation. Recently, Parresol (2001) reported two different examples of SUR by developing further into non-linear regression.

Preliminary exploration of biomass component equations. Scatterplots of the biomass data, stepwise regression procedures, and residual analysis were used to select the best single and multiple regression equations. The dependent variables were the biomass components leaf, branch, and stem and their log-transformations. The explanatory independent variables used were $\mathrm{D}, \mathrm{H}$, the combined variable $D^{2} \mathrm{H}$ and their log-transformations. Goodness of fit statistics were used to select the most appropriate single and multiple variable models. Once the regression equations were selected on the basis of the goodness of fit statistics,

Table 1. Statistics for 56 sample trees used for developing additive biomass equations for three pine species planted in Durango, Mexico

\begin{tabular}{lcccccccc}
\hline SPECIES & \multicolumn{8}{c}{ TREE PARAMETERS } \\
\cline { 2 - 10 } (years) & \multicolumn{2}{c}{$\begin{array}{c}\text { BASAL } \\
\text { DIAMETER } \\
(\mathrm{cm})\end{array}$} & $\begin{array}{c}\text { TOP } \\
\text { HEIGHT } \\
(\mathrm{m})\end{array}$ & $\begin{array}{c}\text { COVER } \\
\left(\mathrm{m}^{2}\right)\end{array}$ \\
\cline { 2 - 10 } & $\mathrm{M}$ & $\mathrm{S}$ & $\mathrm{M}$ & $\mathrm{S}$ & $\mathrm{M}$ & $\mathrm{S}$ & $\mathrm{M}$ & $\mathrm{S}$ \\
\hline P. cooperii & 13,9 & 5,8 & 12,4 & 3,8 & 6,3 & 3,0 & 4,2 & 2,5 \\
\hline P. durangensis & 14,1 & 4,8 & 13,4 & 4,2 & 5,9 & 2,3 & 5,4 & 2,8 \\
\hline P. engelmannii & 14,8 & 5,2 & 12,5 & 3,8 & 4,4 & 1,3 & 5,0 & 3,4 \\
\hline All Species & 14,3 & 5,3 & 12,8 & 3,9 & 5,5 & 2,2 & 4,8 & 2,9 \\
\hline
\end{tabular}


scatterplots of squared residuals and the explanatory variables were regressed to obtain the weigthing equations. Weighting is a statistical procedure required to reduce the increasing biomass variance in larger trees. It is conducted on developing equations to predict the biomass error as a function of the independent variables. Three additive procedures were tested: CON, HAR, and SUR. Examples using one and multiple variables are given in equations (1) and (2), equations (3) and (4) are for CON and HAR additive procedures, respectively. SUR was developed with equations (1) and (2) and the parameters of biomass component equations were restricted to produce total biomass.

The goodness of fit statistics used to select the single and best regression equation were the coefficient of determination or fit index, $r^{2}$, standard error, $\mathrm{Sx}$, coefficient of variation of residuals, CV, mean percent standard error, $\mathrm{S}(\%)$, and percent error, Pe. Information on these statistics is given in Parresol (1999). S(\%) is based on the ratio between the absolute error and the biomass estimate, while $\mathrm{Pe}$ is based on the ratio between the estimated and observed biomass data minus 1. Therefore, $\mathrm{S}(\%)$ and $\mathrm{Pe}$ are estimates of the model deviance.

The goodness of fit statistics were estimated for each biomass component separately. The goodness of fit statistics of the log-transformed linear square procedures are not compatible. Hence, when variables were log-transformed, first the parameters were estimated with the log-transformation procedure and then biomass components were computed by the commonly used correction factor $\left(y=\exp ^{(g(y)+\sigma 2 / 2)}\right)$, where $\sigma 2$ is the variance

$$
\begin{gathered}
\hat{y}_{\text {leaf }}=b_{10}+b_{11}\left(D^{2} H\right) \\
\hat{y}_{\text {branch }}=b_{20}+b_{21}\left(D^{2} H\right) \\
\hat{y}_{\text {stem }}=b_{30}+b_{31}\left(D^{2} H\right) \\
\hat{y}_{\text {total }}=\hat{y}_{\text {leaf }}+\hat{y}_{\text {branch }}+\hat{y}_{\text {stem }}=\left(b_{10}+b_{20}+b_{30}\right)+\left(b_{11}+b_{21}+b_{31}\right)\left(D^{2} H\right) \\
\hat{y}_{\text {leaf }}=b_{10}+b_{11}(D)+\ldots+b_{1 k}\left(D^{2} H\right)+b_{12}(\ln D)+\ldots+b_{1 n}\left(\ln D^{2} H\right) \\
\hat{y}_{\text {branch }}=b_{20}+b_{21}(D)+\ldots+b_{2 k}\left(D^{2} H\right)+b_{2 k+1}(\ln D)+\ldots+b_{2 n}\left(\ln D^{2} H\right) \\
\hat{y}_{\text {stem }}=b_{30}+b_{31}(D)+\ldots+b_{3 k}\left(D^{2} H\right)+b_{3 k+1}(\ln D)+\ldots+b_{3 n}\left(\ln D^{2} H\right) \\
\hat{y}_{\text {total }}=\hat{y}_{\text {leaf }}+\hat{y}_{\text {branch }}+\hat{y}_{\text {stem }} \\
\hat{y}_{\text {total }}=b_{0}+b_{11}\left(D^{2} H\right)+b_{12}\left(D^{2} H\right)+b_{13}\left(D^{2} H\right) \\
\hat{y}_{\text {total }}=b_{0}+\left[b_{11}(D)+\ldots+b_{1 k}\left(\ln D^{2} H\right)\right] \\
+\left[b_{21}(D)+\ldots+b_{2 n}\left(\ln D^{2} H\right)\right]+\left[b_{31}(D)+\ldots+b_{3 m}\left(\ln D^{2} H\right)\right]
\end{gathered}
$$


of the log-transformed regression). Observed and computed biomass in original units provided information to estimate the goodness of fit statistics in compatible units. Least square techniques in nonlinear, linear, multiple regression, multiple regression with dummy variables, linear and In-transformed system of equation procedures was used to compute parameters. The Newton's method in SAS package was employed in the nonlinear procedures.

Comparisons between biomass estimates of independent data sets. The performance of additive procedures has been assessed on the standard error of the parameter estimates. In this report the $t$ values were contrasted among additive procedures since parameter estimates also change with the additive procedure. Additive equations were also applied to all standing trees of each of the 23 quadrants to contrast biomass estimates and confidence intervals for each biomass component for each additive procedure for both species scales.

\section{RESULTS}

Selection of equations for additive procedures. Different goodness of fit statistics resulted from the regression procedures employed to estimate biomass components in simple and multiple regression procedures. Clearly the simple and multiple linear equations fit better biomass components and total. The non-linear (i.e. $B=\alpha D^{\beta}$ ) and the log transformed (i.e. $\ln B=\alpha+\beta \ln \left(D^{2} h\right)$ ) regression equations had the poorest goodness of fit statistics for branch, stem, and total biomass for all species, as well as for each species but because of poor performance the coefficients are not presented in the manuscript. For the simple regression approach, the linear equation, using the combined variable
$\mathrm{D}^{2} \mathrm{H}$ as independent variable, provided the best goodness of fit statistics for stem and total biomass for all species, as well as for each species (Table 2). Therefore, the linear regression using $\mathrm{D}^{2} \mathrm{H}$ as independent variable was used to further explore the additive procedures CON, HAR, and SUR. For all three additive procedures, the biomass component equations are:

$$
\begin{gathered}
y_{\text {leaf }}=b_{10}+b_{11}\left(D^{2} H\right) \\
y_{\text {branch }}=b_{20}+b_{21}\left(D^{2} H\right) \\
y_{\text {stem }}=b_{30}+b_{31}\left(D^{2} H\right) \\
y_{\text {total }}=y_{\text {leaf }}+y_{\text {branch }}+y_{\text {stem }} \\
=b_{40=(10+20+30)}+b_{41=(11+21+31)}\left(D^{2} H\right)
\end{gathered}
$$

The multiple linear regression fit the biomass data better for all biomass components with the exception of the leaf component, in contrast to the log-transformed multiple regression model. Goodness of fit statistics improved by 4 , $9,6,-114$, and $-30 \%$ for the $r^{2}$, Sx, CV, $\mathrm{S}(\%)$, and $\mathrm{Pe}$, when using multiple linear as compared to using log-transformed multiple regression equations to estimate biomass components. Therefore, for the best regression model, the multiple linear regression was used to further develop the CON, HAR, and SUR additive procedures. The final regression equations for each biomass component, for each species, and for all species were the following:

P. duranguensis:

$$
\begin{gathered}
y_{\text {leaf }}=b_{10}+b_{11} D+b_{12} \ln D^{2} H \\
y_{\text {branch }}=b_{20}+b_{21} D^{2} H \\
y_{\text {stem }}=b_{30}+b_{31} D^{2} H \\
y_{\text {total }}=b_{40}+b_{41} D+b_{42} \ln D^{2} H+b_{43} D^{2} H
\end{gathered}
$$


P. cooperii:

$$
\begin{gathered}
y_{\text {leaf }}=b_{10}+b_{11} D^{2} H+b_{12} \ln D+b_{13} \ln D^{2} H \\
y_{\text {branch }}=b_{20}+b_{21} D+b_{22} \ln D \\
y_{\text {stem }}=b_{30}+b_{31} D^{2} H \\
y_{\text {total }}=b_{40}+b_{41} D^{2} H+b_{42} \ln D+b_{43} D \\
+b_{44} \ln D^{2} H
\end{gathered}
$$

P. engelmannii:

$$
\begin{aligned}
y_{\text {leaf }} & =b_{10}+b_{11} D+b_{12} \ln D^{2} H \\
y_{\text {branch }} & =b_{20}+b_{21} D^{2} H \\
y_{\text {stem }} & =b_{30}+b_{31} D+b_{32} \ln D^{2} H \\
y_{\text {total }} & =b_{40}+b_{41} D+b_{42} \ln D^{2} H \\
& +b_{43} D^{2} H
\end{aligned}
$$

All Species:

$$
\begin{gathered}
y_{\text {leaf }}=b_{10}+b_{11} D+b_{12} \ln H \\
y_{\text {branch }}=b_{20}+b_{21} D+b_{22} \ln D \\
y_{\text {stem }}=b_{30}+b_{31} D^{2} H \\
y_{\text {total }}=b_{40}+b_{41} D+b_{42} \ln H+b_{43} \ln D \\
+b_{44} D^{2} H
\end{gathered}
$$

In general, and as expected, the multiple regression procedures improved predictions of biomass components in contrast to the simple regression equations (Table 2). Stem biomass was consistently well predicted by using the single independent variable $\left(D^{2} H\right)$ in both the simple and multiple regression equations. For the rest of biomass components, the goodness of fit statistics improved the coefficient estimates by $19 \%, 44 \%, 10$ $\%$, and $28 \%$ for the $\mathrm{r}^{2}, \mathrm{Sx}, \mathrm{Cv}$, and $\mathrm{Pe}$, respectively, when using multiple linear equations. An equation for each species improves the coefficient estimates when computing total biomass, in contrast to using a single biomass equation for all species. When using the best multiple linear equation, the coefficient estimates improves on the average by $14 \%$.

The weighing equations that predicted the error as a function of the independent variables, resulted in power functions (i.e. $\left.e^{2}=\alpha\left(D^{2} H\right)^{\beta}\right)(37,5 \%)$ and linear (i.e. $\left.e^{2}=\alpha+\beta\left(D^{2} H\right)\right)(62,5 \%)$ functions of the independent variables, stressing the heteroscedasticity of the biomass data (Cunia and Briggs, 1984; Parresol, 1999). This variation was functionally related to the predictor variables in the regression, although the coefficients of determination hardly surpassed 0,50 .

Biomass estimates for trees with equations developed. Additive procedures CON and SUR computed unbiased total biomass when using one independent variable. In contrast the HAR additive procedure (ii) underestimated leaf but overestimated stem biomass components when using one single independent variable for one equation for all species. However, the HAR procedure provided unbiased total biomass estimates for each species. For the best multiple regression models, the SUR procedure slightly overestimated total biomass but for only $P$. engelmannii. The potential causes of this deviation could not be determined. However, a poor regression fitting may have explained this deviation.

\section{Contrasting additive procedures}

Standard errors on the parameter estimates. The standard errors of the parameter estimates are smaller, often by several orders of magnitude in SUR in contrast to $\mathrm{CON}$ and HAR procedures (Table 3). Therefore, the $t$ values are also several orders of magnitude larger when using SUR procedures. For the simple variable equation, the average $t$ values increase approximately $27 \%$ and $1500 \%$ in additive procedure SUR in contrast to 
additive procedures $\mathrm{CON}$ and HAR, respectively. The harmonization procedure also consistently increased the $t$ values in contrast to the CON procedure by an average of $38 \%$. For the best regression equation, the $t$ values increased in additive procedure SUR by $418 \%$ and $4279 \%$ in contrast to the $t$ values estimated for the conventional and harmonization procedures, respectively. The harmonization procedure again consistently had higher $t$ values, on the average $1057 \%$ in contrast to additive procedure CON.

Table 2. Statistics of goodness of fit for selecting a single and a multiple equation to test three additivity procedures for total biomass for pine trees planted in Durango, Mexico

\begin{tabular}{|c|c|c|c|c|c|c|}
\hline \multirow[t]{2}{*}{ SPECIES } & \multirow[t]{2}{*}{ EQUATION } & \multicolumn{5}{|c|}{ GOODNESS OF FIT STATISTICS } \\
\hline & & $r^{2}(\%)$ & $\mathrm{Sx}(\mathrm{kg})$ & $\mathrm{CV}(\%)$ & $\mathrm{S}(\%)$ & $\mathrm{Pe}(\%)$ \\
\hline \multirow{5}{*}{ All species } & LS & 82 & 6,2 & 34 & 22 & 80 \\
\hline & NLS & 68 & 8,1 & 45 & 37 & 104 \\
\hline & LTS & 81 & 6,2 & 35 & 24 & 85 \\
\hline & ML & 86 & 5,6 & 31 & 22 & 81 \\
\hline & MNL & 83 & 6,1 & 34 & 20 & 77 \\
\hline \multirow{5}{*}{ P.durangensis } & LS & 88 & 5,4 & 28 & 22 & 69 \\
\hline & NLS & 62 & 9,9 & 52 & 42 & 289 \\
\hline & LTS & 80 & 7,1 & 37 & 27 & 62 \\
\hline & ML & 89 & 5,6 & 29 & 24 & 67 \\
\hline & MNL & 86 & 6,2 & 32 & 22 & 66 \\
\hline \multirow{5}{*}{ P. cooperii } & LS & 89 & 4,2 & 25 & 16 & 31 \\
\hline & NLS & 73 & 6,8 & 40 & 35 & 148 \\
\hline & LTS & 89 & 4,3 & 26 & 20 & 28 \\
\hline & ML & 94 & 3,6 & 21 & 14 & 22 \\
\hline & MNL & 93 & 3,9 & 23 & 13 & 20 \\
\hline \multirow{5}{*}{$P$. engelmannii } & LS & 86 & 4,9 & 32 & 39 & 69 \\
\hline & NLS & 52 & 9,1 & 59 & 43 & 110 \\
\hline & LTS & 68 & 7,4 & 48 & 24 & 36 \\
\hline & ML & 88 & 5,1 & 33 & 34 & 40 \\
\hline & MNL & 85 & 5,6 & 37 & 18 & 27 \\
\hline
\end{tabular}

LS = Simple Linear

NLS $=$ Simple Non-linear

LTS $=$ Simple Log-transformed
$\mathrm{ML}=$ Multiple Linear

$\mathrm{MNL}=$ Multiple non-linear regression 
Table 3. Parameter (E), standard error (Sx), and changes in $t$ values from fitting three additive techniques for multiple regression models for pine biomass components and total for all species

\begin{tabular}{|c|c|c|c|c|c|c|c|c|c|c|}
\hline \multirow[t]{2}{*}{ S } & \multirow[t]{2}{*}{ P } & \multicolumn{2}{|c|}{$\begin{array}{l}\text { CONVEN- } \\
\text { TIONAL }\end{array}$} & \multicolumn{2}{|c|}{$\begin{array}{l}\text { HARMONI- } \\
\text { ZATION }\end{array}$} & \multicolumn{2}{|c|}{$\begin{array}{l}\text { SEEMINGLY } \\
\text { UNRELATED }\end{array}$} & \multicolumn{3}{|c|}{$\begin{array}{c}\text { REDUCTION IN } t \\
(\%)\end{array}$} \\
\hline & & E & Sx & E & Sx & E & Sx & $1 v s 2$ & $1 v s 3$ & $2 v s 3$ \\
\hline \multirow{13}{*}{$\begin{array}{l}\text { All } \\
\text { Species }\end{array}$} & $b_{10}$ & $-0,43$ & 0,72 & 0,287 & 0,84 & $-1,13$ & 0,35 & -157 & 445 & * \\
\hline & $b_{11}$ & 0,575 & 0,06 & 0,554 & 6,33 & 0,353 & 0,05 & -99 & -19 & * \\
\hline & $b_{12}$ & $-2,82$ & 0,52 & $-3,05$ & 50,3 & $-0,54$ & 0,3 & -99 & -67 & * \\
\hline & $b_{20}$ & 14,95 & 13,3 & 0,287 & 0,84 & 9,413 & 2,28 & -70 & 267 & * \\
\hline & $b_{21}$ & 2,009 & 0,61 & 1,357 & 0,83 & 1,605 & 0,19 & -50 & 157 & 417 \\
\hline & $b_{22}$ & $-14,7$ & 8,33 & $-5,57$ & 4,88 & $-10,3$ & 1,86 & -35 & 216 & 387 \\
\hline & $b_{30}$ & 0,285 & 1,45 & 0,287 & 0,84 & 0,093 & 0,16 & 74 & 196 & 71 \\
\hline & $b_{31}$ & 0,009 & 0,00 & 0,009 & 0,00 & 0,009 & 0,0003 & 76 & 98 & 13 \\
\hline & $b_{40}$ & 14,81 & 6,13 & 0,862 & 0,84 & 8,367 & 2,14 & -58 & 62 & 281 \\
\hline & $b_{41}$ & 2,585 & 0,83 & 1,912 & 1,08 & 1,959 & 0,2 & -43 & 215 & 456 \\
\hline & $b_{42}$ & $-2,82$ & 0,8 & $-3,05$ & 50,3 & $-0,54$ & 0,3 & -98 & -49 & * \\
\hline & $b_{43}$ & $-14,7$ & 6,23 & $-5,57$ & 4,88 & $-10,3$ & 1,86 & -52 & 136 & 387 \\
\hline & $b_{44}$ & 0,009 & 0,00 & 0,009 & 0,00 & 0,009 & 0,0003 & 457 & 528 & 13 \\
\hline
\end{tabular}

Estimates of total stand biomass. The additive procedures computed different biomass component estimates when equations were applied to tree data from 23 planted stands. For a single equation for each pine species, all additive procedures computed similar biomass for the branch, stem, and total components (Fig 1a). For leaf biomass, for the single independent variable and for the multiple regression, all additive procedures computed different biomass estimators. However, the additive procedures SUR and HAR computed similar leaf biomass estimates across single and multiple regression equations. Biomass computations are biased when developing a single equation for all species (Fig 1b). For the single regression equations, the HAR procedure overestimated average leaf biomass.

For multiple regression equations, the SUR regressions overestimated leaf biomass. For the simple equations, the SUR procedure underestimated branch biomass, while for multiple regression equations, the HAR procedure underestimated branch biomass. For the simple regression equations, the HAR procedure overestimated stem biomass. The SUR and the HAR procedures developed in multiple regression underestimated total biomass in contrast to the SUR and HAR developed in simple regression, when developing a single equation for all species. 

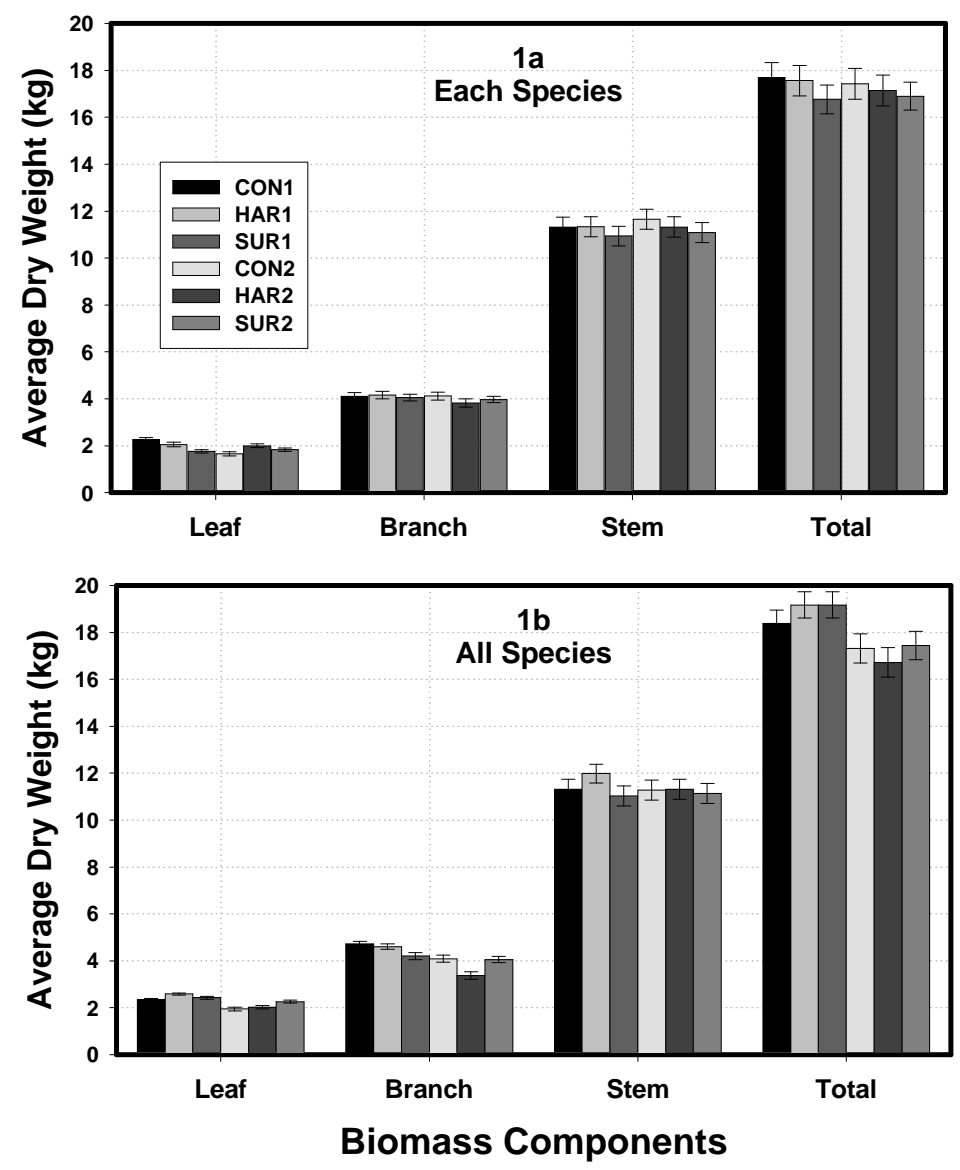

Figure 1. Average biomass and confidence intervals estimated with six different equations in three additive procedures, for simple and multiple regression equations for pine species planted in Durango, Mexico. CON1 = Conventional, HAR1 = harmonization, SUR1 = seemingly-unrelated in simple linear regression, CON2 = Conventional, HAR2 = harmonization, and SUR2 = seemingly-unrelated in multiple linear regression. a) For a single equation developed for each pine species. b) For a single equation developed for all pine species. 


\section{DISCUSSION}

Simple and multiple linear regression equations better fit the biomass component data in contrast to the log-transformed and the non-linear regression equations. This result contrasts with the traditional use of simple non-lineal equations developed in most non-additive allometric studies (e.g., Ter Mikaelian and Korzukhin, 1997; Schroeder et al., 1997). However, the seemingly-unrelated regression equations developed for this study resulted in a best regression equation while the conventional non-linear equations match in a similar way observed total biomass data for each species and for all species for the range of measured data (Fig 2a, 2b, 2c, and 2d). When biomass projections are required below the minimum observed basal diameter ( 5 $\mathrm{cm}$ ), allometric equations developed in SUR overestimate total biomass in trees of the species $P$. engelmannii. Equations developed in SUR for all species also overestimate total biomass in trees with basal diameter less than $2 \mathrm{~cm}$. This was observed when projecting the additive equations in range of $0 \mathrm{~cm}$ to $60 \mathrm{~cm}$ of diameter. However, for the range of observed data, the linear regression equations mimic the non-linear tendency well.
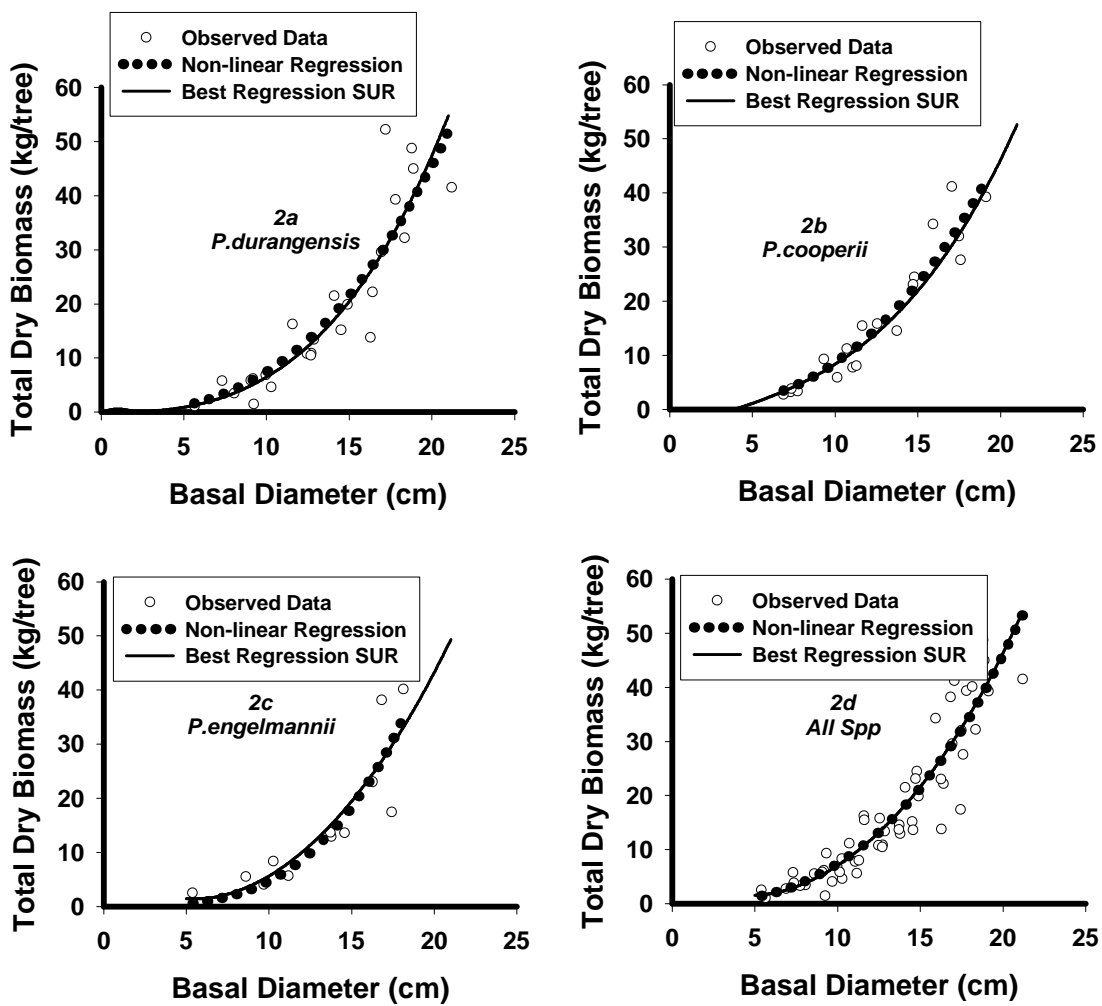

Figure 2. Observed and computed biomass by the conventional non-linear procedures and the resulting equations in seemingly-unrelated regression using the best model for each of three pine species and for all pine species planted in Durango, Mexico. 
The seemingly-unrelated regression clearly is the method of choice for fitting additive biomass component equations. This additive procedure achieves lower variance as seen by the confidence bounds of equation coefficients. Therefore SUR is a more efficient estimator (Parresol, 1999). It is more flexible and takes into account statistical dependencies among sample data by setting constraints on the coefficients (Cunia and Briggs, 1985; Parresol, 1999). Other advantages of using SUR include (a) predictions of the components add up to the prediction for the total tree and (b) the coefficients are more consistent (Cunia and Briggs, 1984; Parresol, 1999).

Moreover, there is an increasing need for estimating biomass compartments for environmental-related issues, productivity, and economic values. However, this procedure is the most difficult additive method to calculate in this analysis, and predictions beyond the characteristics of measured trees are uncertain (Cunia and Briggs, 1984). Extrapolation uncertainty is also a feature of all regressions developed in this study.

Should additive procedures be used to estimate total biomass, attention must be paid to selecting the right equation when quantifying total biomass at the stand scale. In this research, it is shown that different additive equations might provide different biomass estimates, and this finding could also apply to non-additive procedures. Indeed, Woods et al. (1991) found that most of the error in estimating biomass density was attributed to the method of parameter estimation. Another potential sources of error frequently mentioned is the component due to the random selection of the sample unit (Woods et al., 1991; Parresol, 1999). It is a function of the sampling design, the sample size, the type of estimator used, and the inherent variation between the sample units. The exploration of the latter error sources is of paramount importance and should be addressed accordingly to provide reliable stand biomass quantification.

\section{CONCLUSIONS}

Equations to estimate aboveground, standing biomass were developed for three single species and for the set of three, typical of small-scale forest plantations of Durango, Mexico. Equations developed using additive procedures in seemingly-unrelated regressions computed biomass components with the largest efficiency and they were consistent with equations developed in non-additive nonlinear regression. Since they provided average estimates, additive equations in seemingly-unrelated multiple linear regression for each species or all species are recommended to quantify biomass components in biomass inventory of the coniferous forest plantations of Durango, Mexico.

\section{ACKNOWLEDGMENTS}

The Mexican Foundation for Science and Technology and University Fund for Science and Technology funded this project through research grants 28536-B and CN 323-00, respectively.

\section{REFERENCES}

Brown, S. 1997. Los bosques y el cambio climatico: el papel de los terrenos forestales como sumideros de carbono. In: Actas del XI Congreso Mundial Forestal: Recursos Forestales y Arboles. Vol 1. Antalya Turky 13-22 October of 1997.

Clutter, J.L.; J.C. Forston; L.V. Pienaar; G.H. Brister and R.L. Bailey. 1983. 
Timber management: A quantitative approach. Wiley, New York. 333 p.

Cunia, T. and R.D. Briggs. 1984. Forcing additivity of biomass tables - some empirical results. Canadian Journal of Forest Research 14: 376-384.

Cunia, T. and R.D. Briggs. 1985. Forcing additivity of biomass tables - use of the generalized least-square method. Canadian Journal of Forest Research 15: 23-28.

Houghton, R.A. 1991. Tropical deforestation and carbon dioxide. Climate Change 19: 99-118.

Mohren, F. and K. Goldewijk. 1990. $\mathrm{CO}_{2}$ Fix Model. Institute of Forestry and Nature Research. Wageningen, Holanda.

Návar C., J.J.; J. Nájera, and E. Jurado. 2002. Biomass estimation equations in the Tamaulipan thornscrub of northeastern Mexico. Journal of Arid Environments 52:167-179.

Parresol, B. 1999. Assessing tree and stand biomass: a review with examples and critical comparisons. For. Sci. 45:573-593.

Schroeder, P.; S. Brown; J. Mo; R. Birdsey and C. Cieszewski. 1997. Biomass estimation for temperate broadleaf forest of the United States using inventory data. For. Sci. 43:424-434.

Ter-Mikaelian, M.T. and Korzukhin, M.D. 1997. Biomass equations for sixty five North American tree species. Forest Ecology and Management 97:1-24.

Woods, K.D.; A.H. Feiveson and D.B., Botkin. 1991. Statistical analysis for biomass density and leaf-area index estimation. Canadian Journal of Forest Research 21:974-989.» pine species of forest plantations of Durango, Mexico. Madera y Bosques 10(2):17-28. 